\title{
Efeitos da Participação Orçamentária na Assimetria Informacional, Estresse Ocupacional e Desempenho Gerencial
}

Effects of Budgetary Participation on Asymmetry of Information, Occupational Stress and Managerial Performance

Vinicius Costa da Silva Zonatto ${ }^{1}$

https://orcid.org/0000-0003-0823-6774

Aline Weber ${ }^{1}$

https://orcid.org/0000-0002-0047-7357

Juliana Constâncio Nascimento ${ }^{1}$

https://orcid.org/0000-0002-8661-127X

Universidade Regional de Blumenau, Departamento de Contabilidade, Blumenau, SC, Brasil ${ }^{1}$

Artigo recebido em 11.10.2017. Última versão recebida em 12.11.2018. Aprovado em 13.11.2018. 


\title{
Resumo
}

A pesquisa investiga os efeitos da participação orçamentária na assimetria de informação, no estresse ocupacional e no desempenho gerencial junto a 121 gestores com responsabilidade orçamentária em organizações industriais brasileiras. Pesquisa descritiva, realizada por meio de levantamento, cuja abordagem é quantitativa. Os resultados evidenciam que na amostra observada os níveis de participação orçamentária diferem entre os gestores, assim como seu desempenho. A participação e o desempenho estão negativamente associados à ambiguidade de papéis e ao estresse no trabalho. Estes achados sugerem que maiores níveis de participação orçamentária contribuem para a redução da ambiguidade de papéis, dos níveis de estresse ocupacional e o alcance de melhor desempenho. As relações entre assimetria de informação e conflito de papéis com a participação e o desempenho não foram estatisticamente significativas. Estas evidências permitem concluir que a participação orçamentária influencia a ambiguidade de papéis, o estresse no trabalho e o desempenho gerencial, não sendo possível inferir conclusivamente sobre seus efeitos em relação à assimetria de informação e ao conflito de papéis. Fornece evidências de que os efeitos da participação no desempenho ocorrem de maneira direta e indireta, quando mediados pela variável de ambiguidade de papéis.

Palavras-chave: participação orçamentária; assimetria de informação; ambiguidade e conflito de papéis; estresse no trabalho; desempenho gerencial.

\begin{abstract}
The study investigates the effects of budgetary participation on asymmetrical information, occupational stress and managerial performance among 121 managers with budgetary responsibility in Brazilian industrial organizations. Descriptive research was conducted by means of a survey and a quantitative approach. The results indicate that the levels of budgetary participation observed in this sample differ among managers, as does their performance. Participation and performance are negatively associated with role ambiguity and stress at work. These findings suggest that higher levels of budgetary participation contribute to a reduction in role ambiguity and occupational stress levels and the achievement of better performance. The relationships between asymmetry of information and role conflict and participation and performance were not found to be statistically significant. This evidence makes it possible to conclude that budgetary participation influences role ambiguity, stress at work and managerial performance, but it was not possible to infer that it affects the asymmetry of information and role conflict. Thus, we have found that participation affects performance both directly and indirectly when mediated by the variable of role ambiguity.
\end{abstract}

Keywords: budgetary participation; asymmetry of information; role ambiguity and conflict; stress at work; managerial performance.

JEL Codes: D82, L25, O15. 


\section{Introdução}

Uma das técnicas utilizadas pelos gerentes para planejamento e controle é o orçamento empresarial (Davila \& Wouters, 2005), que se constitui em um instrumento de gestão destinado a estabelecer metas e planos organizacionais, alocar recursos, motivar e avaliar os subordinados (Birnberg, Luft, \& Shields, 2006; Covaleski, Evans, Luft, \& Shields, 2006). Esta motivação ocorre a partir da participação dos gestores nos processos orçamentários (Chow, Cooper, \& Waller, 1988). Assim, por meio da participação orçamentária, os gestores de nível médio podem compartilhar informações, de modo que se estabeleça uma alocação mais adequada de recursos, com vistas ao alcance dos objetivos e metas organizacionais (Kyj \& Parker, 2008).

Maior participação orçamentária tem sido associada a uma menor assimetria de informação (Chow et al., 1988; Dunk, 1993; Kyj \& Parker, 2008, Zonatto \& Lavarda, 2013), e menor estresse ocupacional (M. D. Shields, Deng, \& Kato, 2000; Zonatto \& Lavarda, 2013). Por consequência, tornase possível o alcance de melhor desempenho gerencial. Contudo, os achados diante da abordagem comportamental da contabilidade, sobre tais efeitos, ainda não podem ser considerados conclusivos (Derfuss, 2016), lacuna teórica que tem estimulado a realização de novas investigações.

Isto pode ocorrer em casos em que os efeitos da participação orçamentária sobre o desempenho gerencial são indiretos. Nestes casos, a relação entre participação orçamentária e o desempenho gerencial pode ser mediada por variáveis intervenientes (Dani, Zonatto, \& Diehl, 2017; Derfuss, 2016). Tais argumentos podem explicar o porquê a literatura tem apresentado resultados divergentes em relação aos efeitos da participação orçamentária no desempenho gerencial.

Nesta pesquisa, a investigação sobre possíveis efeitos mediadores na relação entre participação orçamentária e desempenho gerencial será observada por meio da assimetria de informação e do estresse ocupacional, avaliado a partir da ambiguidade e do conflito de papéis. Estas variáveis já foram utilizadas em outros estudos desenvolvidos sobre o tema (M. D. Shields et al., 2000; Paschoal \& Tamayo, 2004; Zonatto \& Lavarda, 2013). Enquanto algumas pesquisas têm relatado relação negativa entre a participação orçamentária e a assimetria informacional (Dunk, 1993; Kyj \& Parker, 2008, Zonatto \& Lavarda, 2013), outras evidências permitiram refutar tal associação (Fisher, Frederickson, \& Peffer, 2002; Jermias \& Yigit, 2013, Lavarda \& Almeida, 2013).

O mesmo se observa nas pesquisas que investigaram a relação existente entre participação orçamentária, ambiguidade, conflito de papéis e o estresse ocupacional, pois alguns estudos sugerem uma associação negativa entre a participação orçamentária e estas variáveis (Chenhall \& Brownell, 1988; M. D. Shields et al., 2000; Parker \& Kyj, 2006; Zonatto \& Lavarda, 2013), bem como, com o desempenho gerencial, e outros não encontraram relações diretas entre estas variáveis e o desempenho (Chong, Eggleton, \& Leong, 2006).

Uma possível explicação para estes achados pode estar relacionada à forma como estas variáveis foram utilizadas em outros estudos. Identificou-se na literatura que o constructo de estresse ocupacional proposto por Paschoal e Tamayo (2004) pode não ser o mais adequado para se investigar o estresse no trabalho, uma vez que este ignora os conceitos de ambiguidade de papéis e conflito de papéis, transformando um conjunto de indicadores em um único índice global. A ambiguidade está relacionada à falta de compreensão clara sobre as atividades que devem ser realizadas para o desenvolvimento de um trabalho correto e eficiente (Kahn, Wolfe, Quinn, Snoek, \& Rosenthal, 1964). Já os conflitos de papéis estão relacionados à falta de estrutura no trabalho para o desenvolvimento das atividades (Rizzo, House, \& Lirtzmann, 1970). Portanto, entende-se que se referem a estressores distintos presentes no ambiente de trabalho, motivo pelo qual podem gerar respostas distintas dos indivíduos.

Por esta razão, para a realização desta pesquisa foi utilizado o constructo proposto por Rizzo, House e Lirtzmann (1970), pois permite realizar a análise individual de cada elemento (ambiguidade e conflito de papéis) e sua análise conjunta, esta que se refere ao estresse ocupacional. A investigação 
separada de tais elementos (ambiguidade e conflito de papéis) permite ao pesquisador evidenciar resultados distintos nas organizações, qualificando a compreensão de tais relacionamentos, o que pode não ser observado quando da análise do estresse apenas como um índice global. Tais premissas reforçam a relevância desta pesquisa.

Do mesmo modo, uma possível explicação para a identificação de resultados divergentes na literatura pode se dar pela métrica utilizada para investigar o desempenho gerencial. Neste caso, utiliza-se a abordagem proposta por Mahoney, Jerdee e Carroll $(1963,1965)$ que, além de mais ampla (engloba nove indicadores diferentes de desempenho), foi desenvolvida especificamente para avaliar o desempenho de gestores de organizações industriais, a partir de suas funções desempenhadas no cotidiano do seu trabalho (Zonatto, 2014), contexto em que a pesquisa foi desenvolvida.

Tais aspectos distinguem este de outros trabalhos desenvolvidos sobre o tema (Paschoal \& Tamayo, 2004; Zonatto \& Lavarda, 2013), constituindo-se em diferenciais que contribuem para o avanço da discussão teórica de tais relacionamentos no campo de estudos da abordagem comportamental da contabilidade. Esta abordagem é a denominação apresentada aos estudos que buscam investigar aspectos relacionados a estados mentais, cognição, atitudes e comportamentos dos indivíduos no ambiente de trabalho (Birnberg et al., 2006; Dani et al., 2017).

Assim, em vista dos resultados conflitantes encontrados na abordagem comportamental da contabilidade, bem como tais premissas de análise que reforçam a lacuna de pesquisa existente em relação aos efeitos intervenientes de estressores do trabalho na relação entre participação orçamentária e o desempenho gerencial, busca-se com esta pesquisa fornecer evidências destas relações em um novo contexto de investigação.

Assim, a questão problema do estudo é: Quais os efeitos da participação orçamentária na assimetria de informação, no estresse ocupacional e no desempenho gerencial? O objetivo desta pesquisa consiste em avaliar, junto a gestores de organizações industriais brasileiras, os efeitos da participação orçamentária na assimetria de informação, no estresse ocupacional e no desempenho gerencial. O desempenho gerencial observado nesta pesquisa refere-se ao grau em que os gestores com responsabilidades orçamentárias obtêm êxito no desenvolvimento de suas tarefas (Parker \& Kyj, 2006). Abrange atividades de planejamento, investigação, coordenação, avaliação, supervisão, seleção, negociação, representação e desempenho global (Mahoney, Jerdee, \& Carroll, 1963, 1965).

A pesquisa justifica-se por fornecer evidências da relação direta entre a participação orçamentária e o desempenho gerencial e indireto mediada pelas variáveis de assimetria de informação e estresse ocupacional (avaliado pela ambiguidade, pelo conflito de papéis e como um índice global). Do mesmo modo, fornece evidências dos efeitos de tais variáveis sobre o desempenho do gerente com responsabilidade orçamentária, bem como os efeitos da participação sobre as variáveis intervenientes investigadas na pesquisa. $\mathrm{O}$ estudo também fornece evidências de como determinadas variáveis (tempo de trabalho na empresa e função, nível hierárquico, uso do orçamento para avaliação de desempenho, nível de conhecimentos em gestão de custos, rotinas e processos orçamentários) podem influenciar estas relações. Tais achados se constituem como contribuições teóricas desta pesquisa.

\section{Fundamentação Teórica e Hipóteses da Pesquisa}

\section{Participação orçamentária e desempenho gerencial}

Cada empresa tem uma forma para organizar seu orçamento, levando em consideração a estrutura humana, operacional e tecnológica de capital (Hansen \& Van der Stede, 2004; Lavarda \& Almeida, 2013). Nesse sentido, para a realização das tarefas que dizem respeito ao orçamento, as organizações devem delegar e buscar o envolvimento dos funcionários neste processo, pois são os recursos e práticas organizacionais queapoiam os comportamentos dos gestores e o seu desempenho no trabalho (Macinati, Bozzi, \& Rizzo, 2016). 
Dentre estas práticas que apresentam efeitos positivos no desempenho gerencial está a participação orçamentária (Birnberg et al., 2006), que diz respeito a um processo por meio do qual os funcionários possuem envolvimento e influência na determinação do orçamento de suas unidades (Chong \& Chong, 2002a; J. F. Shields \& Shields, 1998; Milani, 1975).

Quando isto ocorre, a participação orçamentária passa a ser considerada a base para a gestão de metas, objetivos e recursos organizacionais. Além disso, deve motivar os gestores para atingir os objetivos orçamentários e organizacionais (Derfuss, 2009), o que resulta em efeitos no desempenho do trabalho (Derfuss, 2016). Sob a abordagem comportamental da contabilidade, o orçamento tem sido estudado como um artefato de controle gerencial capaz de influenciar a mente e o comportamento dos gestores (Birnberg et al., 2006; Covaleski et al., 2006; Zonatto, 2014). Evidências encontradas na literatura sugerem que elevados níveis de participação orçamentária estão associados positivamente ao desempenho (Brownell, 1982a; Chong \& Chong, 2002a; Chong et al., 2006; Chong \& Johnson, 2007; Dunk, 1993; Nouri \& Parker, 1998; Parker \& Kyj, 2006).

Esta condição é alcançada quando os gestores participam ativamente do processo, compartilhando informações de suas unidades divisionais (Parker \& Kyj, 2006), pois o compartilhamento de informações permite a adequação do orçamento (Nouri \& Parker, 1998). Uma vez que metas e objetivos organizacionais são comunicados, a partilha de informações pode facilitar a alocação de recursos, de modo que estes sejam suficientes para contribuir com a viabilização do desenvolvimento das atividades na unidade sob a responsabilidade do gestor. Neste contexto, a primeira hipótese a ser testada nesta pesquisa assume que: H1. Existe relação positiva entre a participação orçamentária e o desempenho gerencial.

\section{Participação orçamentária e assimetria de informação}

Os orçamentos utilizados para fins de planejamento, coordenação de atividades, avaliação de desempenho e controle (Davila \& Wouters, 2005; Hansen \& Van der Stede, 2004), são resultados de um processo de negociação entre as partes envolvidas. Conforme Fisher, Frederickson e Peffer (2002), este processo pode fornecer explicações para o entendimento de como a assimetria informacional emerge nos processos orçamentários de uma organização.

Nesse sentido, a participação orçamentária tem sido apontada como um meio para reduzir a assimetria de informação existente nos processos orçamentários (Dunk, 1993). Contudo, a assimetria de informação existe apenas quando a informação dos subordinados excede a de seus superiores (Dunk, 1993), por adquirirem informações privadas durante a realização de suas funções (Penno, 1984). A assimetria de informações refere-se à informação que é conhecida pelos funcionários, mas desconhecida pelos superiores, havendo um desequilíbrio da informação entre superior e seus subordinados (Penno, 1984).

A assimetria de informação também está relacionada aos pressupostos da Teoria da Agência (Jensen \& Meckling, 1976), pois esta teoria enfoca a relação entre o principal e o agente. Nesta relação podem ocorrer problemas de agência quando os gestores, no caso desta pesquisa, com responsabilidades orçamentárias, tomam decisões com o intuito de maximizar sua utilidade pessoal e não a riqueza de todos os acionistas (Jensen \& Meckling, 1976). Além disso, a essência da assimetria é que o subordinado (agente) detém informações privilegiadas em comparação com o seu superior (principal) (Jensen \& Meckling, 1976).

De acordo com J. F. Shields e Shields (1998), uma das razões para a participação dos subordinados no processo orçamentário é o compartilhamento de informações entre subordinado e seu superior, o que inclui o compartilhamento de informações privadas que são detidas pelos subordinados. Assim, maior participação orçamentária tem sido associada a menores níveis de assimetria de informação (Chow et al., 1988; J. F. Shields \& Shields, 1998; Kyj \& Parker, 2008; M. D. Shields \& Young, 1993; Zonatto \& Lavarda, 2013). Porém, há relatos de outros estudos que apontam para uma relação não significativa entre tais variáveis (Fisher et al., 2002; Jermias \& Yigit, 2013; 
Lavarda \& Almeida, 2013), o que sugere que a participação orçamentária pode não ser suficiente para reduzir a assimetria informacional existente nos processos orçamentários.

Há que se considerar ainda que em algumas organizações, a participação orçamentária ocorre de maneira cerimonial, em que os gestores são apenas comunicados das previsões estabelecidas pela alta gestão. Logo, a assimetria tende a ser maior nestas organizações, visto que não há um mecanismo capaz de possibilitar a diminuição da assimetria de informação existente, como a participação orçamentária ativa de gestores subordinados. Segundo M. D. Shields e Young (1993) e J. F. Shields e Shields (1998), quanto maior a assimetria de informação entre o subordinado e o seu superior, mais provável que as organizações promovam a participação orçamentária com o intuito de obter informações privadas dos subordinados.

Nesse sentido, no que tange à assimetria de informação entre superior e seus subordinados, Baiman (1990) explica que gestores de unidades divisionais possuem informações privilegiadas, por possuírem conhecimentos das atividades desenvolvidas nas suas unidades de atuação. Assim, entendese que a participação orçamentária só apresentará relação negativa com a assimetria de informação se esta for ativa, em que os gestores de nível médio estejam dispostos a compartilhar informações de suas unidades, e se os objetivos e metas organizacionais estabelecidos são adequados, considerando a quantidade de recursos definida pelos superiores para o desenvolvimento das atividades. Para tanto, a segunda hipótese a ser testada nesta pesquisa assume que, nestas condições: H2. Existe relação negativa entre a participação orçamentária e a assimetria de informação.

\section{Participação orçamentária e estresse ocupacional}

O orçamento tem sido estudado como um mecanismo capaz de reduzir os níveis de estresse relacionado ao trabalho (M. D. Shields et al., 2000). Hopwood (1976) foi um dos primeiros pesquisadores na área contábil a propor que o processo orçamentário pode funcionar como um mecanismo de comunicação, por meio do qual os subordinados obtêm mais informações sobre suas tarefas, o que tende a diminuir o estresse no trabalho.

O estresse ocupacional resulta da percepção dos indivíduos de que as condições de trabalho não são adequadas ao que este necessita para o desenvolvimento de suas tarefas (Paschoal \& Tamayo, 2004). Pode ter origem física, psicológica ou psicossocial, sendo definido como uma pressão imposta ao indivíduo (Selye, 1956). No contexto orçamentário, está relacionado aos efeitos de tais percepções sobre o desempenho do gerente em suas atividades (M. D. Shields et al., 2000; Zonatto \& Lavarda, 2013).

O termo estresse indica uma síndrome de adaptação a um grupo de reações prejudiciais e atuante sobre a organização ou o indivíduo por uma força externa e revela pressão, angústia e tensão (Ursin \& Eriksen, 2004). Fatores emocionais tendem a impactar o comportamento dos indivíduos no trabalho. Assim, situações que geram elevados níveis de insegurança, irritação e ansiedade, tendem a impactar negativamente o grau de esforço em que o indivíduo está disposto a empreender em suas atividades, o que poderá refletir em perda de produtividade e qualidade das atividades desenvolvidas (M. D. Shields et al., 2000; Zonatto \& Lavarda, 2013).

Os fatores estressores tendem a afetar, positiva ou negativamente, o desempenho dos gestores (Cavanaugh, Boswell, Roehling, \& Boudreau, 2000; Mackie, Holahan \& Gottlieb, 2001), dependendo da resposta do indivíduo ao estímulo estressor (Selye, 1956). Pode não ser somente um processo danoso ao indivíduo, pois pode também possibilitar o crescimento, prazer, desenvolvimento intelectual e emocional (Pereira et al., 2003).

Diferentemente de outros estudos desenvolvidos sobre o tema (Paschoal \& Tamayo, 2004; Zonatto \& Lavarda, 2013), nesta pesquisa, os estressores investigados estão relacionados à ambiguidade de papéis, que trata da falta de compreensão clara pelos indivíduos sobre as atividades que devem ser realizadas para o desenvolvimento de um trabalho correto e eficiente (Kahn et al., 1964), e o conflito de papéis, que discute a falta de estrutura no trabalho para que este indivíduo possa

RAC, Rio de Janeiro, v. 23, n. 1, art. 4, pp. 67-91, janeiro/fevereiro, 2019, http://rac.anpad.org.br (cc) 
desenvolver suas atividades (Rizzo et al., 1970). Estes constructos já foram utilizados por outros pesquisadores para discutir o tema no contexto orçamentário (Chenhall \& Brownell, 1988; Chong et al., 2006; Palomino \& Frezatti, 2016).

Chenhall e Brownell (1988) encontraram evidências de que a participação orçamentária está ligada negativamente com a ambiguidade de papéis. A partir deste resultado, argumentam que, por meio da participação orçamentária, os subordinados ganham informações que os auxiliam a esclarecer seus papéis organizacionais, o que inclui seus deveres, responsabilidades e desempenho no trabalho.

Evidências encontradas na literatura sugerem que elevados níveis de participação orçamentária reduzem a ambiguidade e o conflito de papéis, o que resulta em menores níveis de estresse ocupacional (M. D. Shields et al., 2000; Parker \& Kyj, 2006; Zonatto \& Lavarda, 2013), bem como, a ambiguidade de papéis pode levar a menor desempenho no trabalho (Parker \& Kyj, 2006). Chenhall e Brownell (1988) e Jermias e Yigit (2013) somente analisaram a ambiguidade de papéis e também constataram uma relação negativa entre participação orçamentária e ambiguidade de papéis e esta variável com o desempenho.

Conforme Chenhall e Brownell (1988), funcionários que não compreendem plenamente seus deveres e responsabilidades, isto é, aqueles com alta ambiguidade de papéis, hesitarão em tomar decisões por tentativa e erro. Nesse sentido, elevada ambiguidade de papéis indica que um empregado é incerto sobre suas tarefas na organização, o que inclui incertezas sobre suas expectativas organizacionais e os meios necessários para cumpri-las (Parker \& Kyj, 2006).

Todavia, há evidências as quais sugerem que, mesmo os gestores participando dos processos orçamentários, sua participação por si só pode não ser suficiente para que a redução da ambiguidade e conflito de papéis ocorra. Resultados encontrados por Palomino e Frezatti (2016) revelaram que controladores brasileiros perceberam o conflito e a ambiguidade de papéis enquanto desempenharam suas atividades. No entanto, a satisfação destes profissionais foi afetada de maneira diferente por estas variáveis. Logo, pode-se admitir que o mesmo possa ocorrer em relação aos efeitos da participação orçamentária nestas variáveis e os efeitos mediadores do estresse ocupacional, quando avaliado de maneira global ou individual (por meio do conflito e da ambiguidade), na relação entre participação e o desempenho gerencial.

Neste contexto, a terceira hipótese a ser testada assume que, em condições de maior participação orçamentária: H3. Existe relação negativa entre a participação orçamentária e a ambiguidade (H3a), o conflito de papéis (H3b) e o estresse ocupacional (H3c).

\section{Efeitos indiretos da participação orçamentária sobre o desempenho gerencial}

Apesar de o orçamento ter sido apontado como um meio para motivar os gestores a desenvolverem suas atividades de trabalho (Chong et al., 2006; Chow et al., 1988), as evidências encontradas sobre os efeitos diretos da participação orçamentária no desempenho têm apresentado resultados divergentes (Derfuss, 2016), o que indica que a participação orçamentária pode influenciar o desempenho gerencial por meio de variáveis intervenientes (Dani et al., 2017; Derfuss, 2016).

No caso das variáveis investigadas nesta pesquisa, os resultados encontrados na literatura sugerem que tais efeitos podem ocorrer em casos de elevados níveis de participação orçamentária. Chong e Eggleton (2007) encontraram efeitos distintos em relação ao desempenho gerencial, em situações opostas de assimetria de informação (alta ou baixa), o que é explicado pelo comportamento dos gestores. Lavarda e Almeida (2013) evidenciaram que a participação por si só pode não ser suficiente para reduzir os níveis de assimetria informacional, impactando positivamente sobre o desempenho.

Segundo Chong e Chong (2002a), são os papéis informativos da participação do indivíduo nos processos orçamentários que determinam tal influência sobre o desempenho gerencial. Assim, em condições de elevada participação orçamentária, espera-se que possa ocorrer maior partilha de 
informações (M. D. Shields et al., 2000; Parker \& Kyj, 2006; Zonatto \& Lavarda, 2013), o que permite admitir que, nestes casos, ocorra uma redução nos níveis de assimetria informacional, resultando em uma influência indireta e positiva da participação orçamentária sobre o desempenho. Há de se considerar que os gestores podem reter informações no processo orçamentário, de modo que obtenham uma previsão mais adequada às suas necessidades de trabalho, o que lhes permitirá mais facilmente alcançar os objetivos e metas estabelecidos. A quarta hipótese a ser testada nesta pesquisa assume que, em condições de maior participação orçamentária: H4. Existe um efeito mediador da assimetria de informação na relação entre a participação orçamentária e o desempenho gerencial.

Em relação ao estresse ocupacional, M. D. Shields, Deng e Kato (2000) revelaram que, a partir de uma configuração padrão participativa, há uma influência mediadora do estresse relacionado ao trabalho sobre o desempenho gerencial. Estes resultados corroboram com os achados de Parker e Kyj (2006), que sugerem que o compartilhamento de informações entre supervisor e subordinado, em ambos os sentidos, reduz a ambiguidade de papéis, resultando em melhores níveis de desempenho. Tais evidências reforçam os indícios de um efeito mediador do estresse ocupacional, na relação entre participação e desempenho.

Efeitos indiretos da participação orçamentária sobre o desempenho gerencial também foram encontrados por Chenhall e Brownell (1988), Chong, Eggleton e Leong (2006) e Jermias e Yigit (2013), sendo a ambiguidade de papéis uma variável interveniente. Nesse sentido, ao participar dos processos orçamentários, torna-se possível compartilhar informações relevantes para as tarefas (J. F. Shields \& Shields, 1998; Kren, 1992), o que contribui para a redução da ambiguidade (Chenhall \& Brownell, 1988; Kren, 1992), conflito de papéis (Burkert, Fischer, \& Schäffer, 2011; Leach-López, Stammerjohan, \& McNair, 2008), redução dos níveis de estresse ocupacional e o alcance de melhor desempenho (Zonatto \& Lavarda, 2013).

Assim, nos casos em que se pode observar maiores níveis de participação orçamentária, esperase que a partilha de informações reduza a ambiguidade e o conflito de papéis e, os níveis de estresse ocupacional, o que resulta em maior desempenho. Neste contexto, a quinta hipótese a ser testada assume que, nestas condições: H5. A ambiguidade (H5a), o conflito de papéis (H5b) e o estresse ocupacional (H5c) medeiam a relação entre a participação orçamentária e o desempenho gerencial.

\section{Método e Procedimentos da Pesquisa}

A pesquisa caracteriza-se como descritiva, realizada por meio de levantamento e quantitativa. Participaram da pesquisa 121 gestores com responsabilidade orçamentária de organizações industriais brasileiras de grande porte. $\mathrm{O}$ critério de seleção dos respondentes adotado nesta pesquisa é convergente aos observados em estudos desenvolvidos diante da abordagem comportamental da contabilidade, como Lau e Eggleton (2004), Agbejule e Saarikoski (2006), Chong e Johnson (2007) e Chong e Eggleton (2007).

Para a seleção da amostra, inicialmente foi estabelecido um contato com os gestores selecionados para a pesquisa, de modo a se identificar se sua organização utiliza orçamento e se este possui alguma responsabilidade para estabelecer o orçamento. Tais questões são as mesmas utilizadas por Chong et al. (2006) para a definição dos sujeitos da pesquisa. De posse da confirmação de tais informações e o aceite destes gestores em participarem voluntariamente da pesquisa, procedeuse o encaminhamento do questionário utilizado para a coleta dos dados.

O instrumento utilizado para a coleta dos dados é um questionário composto por 33 questões objetivas de múltipla escolha, que foi elaborado a partir dos constructos de: (a) participação orçamentária (6 questões): Milani (1975); (b) assimetria de informação (4 questões): Dunk (1993); (c) 
ambiguidade, conflito de papéis e estresse ocupacional (14 questões): Rizzo et al. (1970); e, (d) desempenho gerencial (9 questões): Mahoney et al. (1963, 1965). Para avaliação do estresse ocupacional, procedeu-se a análise individual de cada uma das escalas de ambiguidade e de conflito de papéis, e a análise global do índice de estresse no trabalho, elaborado a partir da soma dos resultados dessas escalas, como proposto por Paschoal e Tamayo (2004).

Estes constructos têm sido utilizados em outros estudos desenvolvidos sobre o tema para se investigar tais relacionamentos, como M. D. Shields et al. (2000), Nouri e Parker (1998), Chong e Chong (2002a), Chong et al. (2006), Parker e Kyj (2006), Chong e Johnson (2007) e Zonatto e Lavarda (2013). Como nestes estudos, todas as afirmativas foram constituídas em uma escala de resposta do tipo Likert, de 7 pontos, que mede para os constructos de participação orçamentária, assimetria de informação, ambiguidade e conflito de papéis, o nível de concordância dos gestores em relação as afirmativas apresentadas, em que 1 representa o nível máximo de discordância (Discordo Totalmente) e 7 o nível máximo de concordância (Concordo Totalmente). Para o desempenho gerencial, a escala utilizada contempla a auto avaliação do gestor em relação ao seu desempenho em atividades orçamentárias, avaliado a partir de uma análise comparativa ao desempenho de outros gestores de nível médio (do mesmo nível hierárquico de suas atividades na organização), em que 1 representa um desempenho abaixo da média e 7 o oposto (desempenho acima da média).

Para investigar possíveis efeitos de variáveis que podem afetar as relações testadas no estudo, procedeu-se, na análise dos resultados, a inclusão de variáveis de controle, como tempo de trabalho na empresa e na função, nível hierárquico, uso do orçamento para avaliação de desempenho, nível de conhecimentos em gestão de custos e rotinas e processos orçamentários. Desta forma, torna-se possível inferir sobre seus efeitos na amostra selecionada para a realização da pesquisa. Adicionalmente, destaca-se que eventuais efeitos relacionados a diferentes níveis de autonomia podem ser avaliados pelos diferentes níveis de participação orçamentária relatados pelos participantes da pesquisa, bem como pelos níveis de assimetria de informação, o que, por consequência, poderá refletir nas relações avaliadas.

Os dados coletados foram tabulados em planilhas eletrônicas e, após, importados para o software SPSS ${ }^{2}$ 22.0, para tratamento estatístico. Inicialmente, procedeu-se a avaliação de dados ausentes, em que todos os 121 questionários foram mantidos, pois foram preenchidos adequadamente. Realizada esta avaliação, procedeu-se a análise fatorial para a validação dos constructos teóricos de mensuração, conforme procedimentos recomendados por Hair, Black, Babin, Anderson, \& Tatham (2009). Neste caso, foram observados o agrupamento dos indicadores em seus respectivos constructos, as cargas fatoriais (mínimo 0,60) e os resultados da significância do teste de esfericidade de Bartlett e do teste de KMO, além da Variância Total Explicada.

Realizada a avaliação e purificação dos constructos, na sequência, realizou-se a análise dos dados por meio de estatística descritiva, matriz de correlações e análise de caminhos. Tais procedimentos são convergentes aos adotados em estudos desenvolvidos sob a abordagem comportamental da contabilidade (Chong et al., 2006; Nouri \& Parker, 1998).

\section{Descrição e Análise dos Resultados}

Nesta seção apresenta-se a análise descritiva do perfil dos respondentes, a análise fatorial, descritiva dos constructos e a análise de trajetórias. Por fim, evidencia-se uma análise adicional, por meio de uma regressão linear múltipla, com vistas a avaliar se as variáveis que compõem o perfil dos gestores são capazes de influenciar as variáveis analisadas na pesquisa.

O perfil dos gestores participantes da pesquisa revela que estes profissionais apresentam, em média, 38 anos de idade. Destes, 94 são do sexo masculino. O tempo de trabalho médio destes profissionais na empresa em que atuam é de 9 anos e o tempo médio de trabalho na função atual 
exercida é de 5 anos. O nível hierárquico da função destes gestores pode ser considerado alto (média 5,61 ), assim como o uso avaliativo do orçamento pela organização (média 5,74). A percepção destes gestores em relação ao seu nível de conhecimentos em gestão de custos (média 5,97) e em rotinas e processos orçamentários (média 5,93) também é elevada.

Os resultados da análise fatorial e a estatística descritiva dos constructos analisados são apresentados na Tabela 1.

Tabela 1

Resultados da Análise Fatorial e Estatística Descritiva

\begin{tabular}{|c|c|c|c|c|c|c|c|c|c|c|c|}
\hline Var. & $\mathbf{A C}$ & KMO & TEB & VTE & Mín. & Máx. & Méd. & DP & Ind. & $\mathbf{C F}$ & Com. \\
\hline \multirow{6}{*}{ 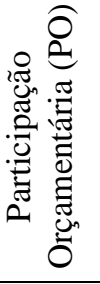 } & \multirow[t]{6}{*}{0,911} & \multirow[t]{6}{*}{0,874} & \multirow{6}{*}{$\begin{array}{l}483,904 \\
(0,000)^{*}\end{array}$} & \multirow[t]{6}{*}{$69,447 \%$} & \multirow[t]{6}{*}{8} & \multirow[t]{6}{*}{35} & \multirow[t]{6}{*}{29,78} & \multirow[t]{6}{*}{5,70} & PO01 & 0,891 & 0,794 \\
\hline & & & & & & & & & $\mathrm{PO} 02$ & 0,700 & 0,491 \\
\hline & & & & & & & & & $\mathrm{PO} 03$ & 0,829 & 0,688 \\
\hline & & & & & & & & & PO04 & 0,872 & 0,760 \\
\hline & & & & & & & & & PO05 & 0,788 & 0,621 \\
\hline & & & & & & & & & PO06 & 0,902 & 0,813 \\
\hline \multirow{4}{*}{ 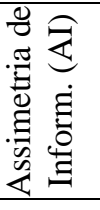 } & \multirow[t]{4}{*}{0,902} & \multirow[t]{4}{*}{0,843} & \multirow{4}{*}{$\begin{array}{l}297,136 \\
(0,000)^{*}\end{array}$} & \multirow[t]{4}{*}{$77,488 \%$} & \multirow[t]{4}{*}{4} & \multirow[t]{4}{*}{25} & \multirow[t]{4}{*}{15,98} & \multirow[t]{4}{*}{5,10} & AI01 & 0,872 & 0,761 \\
\hline & & & & & & & & & $\mathrm{AI} 02$ & 0,862 & 0,743 \\
\hline & & & & & & & & & AI03 & 0,900 & 0,810 \\
\hline & & & & & & & & & $\mathrm{AI} 04$ & 0,886 & 0,786 \\
\hline \multirow{6}{*}{ 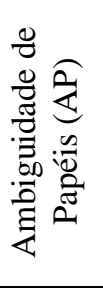 } & \multirow[t]{6}{*}{0,806} & \multirow[t]{6}{*}{0,800} & \multirow{6}{*}{$\begin{array}{l}227,891 \\
(0,000)^{*}\end{array}$} & \multirow[t]{6}{*}{$51,686 \%$} & \multirow[t]{6}{*}{4} & \multirow[t]{6}{*}{21} & \multirow[t]{6}{*}{9,09} & 3,80 & AP01 & 0,591 & 0,350 \\
\hline & & & & & & & & & AP02 & 0,659 & 0,434 \\
\hline & & & & & & & & & AP03 & 0,671 & 0,450 \\
\hline & & & & & & & & & AP04 & 0,773 & 0,598 \\
\hline & & & & & & & & & AP05 & 0,858 & 0,737 \\
\hline & & & & & & & & & AP06 & 0,730 & 0,533 \\
\hline & 0,860 & 0,863 & 369,050 & $50,881 \%$ & 6 & 40 & 24,04 & 7,77 & CP01 & 0,628 & 0,394 \\
\hline ש & & & $(0,000)^{*}$ & & & & & & CP02 & 0,681 & 0,464 \\
\hline$i \frac{\infty}{2}$ & & & & & & & & & $\mathrm{CP} 03$ & 0,601 & 0,361 \\
\hline $\bar{\sigma}$ & & & & & & & & & CP04 & 0,667 & 0,445 \\
\hline \& & & & & & & & & & CP05 & 0,826 & 0,682 \\
\hline : & & & & & & & & & CP06 & 0,721 & 0,520 \\
\hline है & & & & & & & & & CP07 & 0,793 & 0,629 \\
\hline U & & & & & & & & & CP08 & 0,759 & 0,577 \\
\hline (0) & 0,878 & 0,891 & 444,065 & $51,456 \%$ & 20 & 45 & 36,77 & 4,79 & DG01 & 0,749 & 0,560 \\
\hline$\stackrel{\ominus}{=}$ & & & $(0,000)^{*}$ & & & & & & DG02 & 0,724 & 0,524 \\
\hline$\frac{\pi}{0}$ & & & & & & & & & DG03 & 0,704 & 0,495 \\
\hline ల్ల & & & & & & & & & DG04 & 0,793 & 0,629 \\
\hline 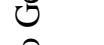 & & & & & & & & & DG05 & 0,697 & 0,486 \\
\hline$\frac{8}{7}$ & & & & & & & & & DG06 & 0,516 & 0,266 \\
\hline$\stackrel{\mathscr{0}}{\approx}$ & & & & & & & & & DG07 & 0,770 & 0,593 \\
\hline $\bar{D}$ & & & & & & & & & DG08 & 0,704 & 0,496 \\
\hline ๑ & & & & & & & & & DG09 & 0,762 & 0,581 \\
\hline
\end{tabular}

Nota. AC: Alfa de Cronbach; KMO: medida de adequação da amostra; TEB: Teste de esfericidade de Bartlett; VTE: Variância Total Explicada; Mín.: Mínimo; Máx.: Máximo; Méd.: Média; DP: Desvio Padrão; Ind.: Indicador; CF: Carga Fatorial; Com.: Comunalidades. Fonte: Dados da pesquisa.

*Significância ao nível de $1 \%$.

Os resultados indicam o agrupamento de todas as variáveis nos seus constructos de mensuração. Os coeficientes Alfa de Cronbach de cada constructo foram superiores a 0,8 e os indicadores do teste 
de Kaiser-Meyer-Olkin (KMO). Os resultados do teste de esfericidade de Bartlett revelaram adequação das análises realizadas para avaliar a consistência geral dos dados. O mesmo se observa em relação à Variância Total Explicada, superior a 50\% em todos os casos analisados. Isso indica que a composição final destes constructos é adequada para a análise de trajetórias e possuem um elevado poder explicativo para as relações investigadas na pesquisa.

Os resultados da estatística descritiva revelam que os níveis de participação orçamentária diferem entre as organizações pesquisadas. Estes resultados revelam que, em algumas organizações, estes gestores não percebem sua influência nos processos orçamentários. Quando isto ocorre, seu desempenho gerencial pode ser afetado negativamente (Kyj \& Parker, 2008; Zonatto \& Lavarda, 2013). Mesmo participando, quando esta participação não é ativa, os efeitos da participação sobre o desempenho também podem não ser os esperados. Além desta possibilidade, Lavarda e Almeida (2013) explicam que a assimetria de informação pode ocorrer por meio do próprio comportamento dos gestores, estes que, muitas vezes, relutam em compartilhar informações. Os gestores de unidades tendem a possuir maiores informações (Baiman, 1990; Parker \& Kyj, 2006). Quando metas são instituídas pelos superiores sem a efetiva participação de todos os envolvidos, a assimetria poderá elevar o estresse ocupacional (Zonatto \& Lavarda, 2013) e influenciar negativamente o desempenho (Dunk, 1993).

A este respeito, evidências encontradas na literatura (Cavanaugh et al., 2000; Mackie et al., 2001) sugerem que o estresse pode influenciar positivamente o desempenho no trabalho. Isto ocorre quando os indivíduos aceitam as metas e objetivos organizacionais.

A Tabela 2 apresenta os resultados da análise das correlações.

Tabela 2

\section{Matriz de Correlações}

\begin{tabular}{lllllll}
\cline { 2 - 6 } & PO & AI & AP & CP & ET & DG \\
\hline Participação Orçamentária (PO) & 1 & & & & & \\
\hline Assimetria de Informação (AI) & $-0,046$ & 1 & & & & \\
\hline Ambiguidade de Papéis (AP) & $-0,640^{* *}$ & $-0,115$ & 1 & & & \\
\hline Conflito de Papéis (CP) & $-0,101$ & $-0,357^{* *}$ & 0,072 & 1 & & \\
\hline Estresse no Trabalho (ET) & $-0,362^{* *}$ & $0,258^{* *}$ & $0,490^{* *}$ & $0,905^{* *}$ & 1 & \\
\hline Desempenho Gerencial (DG) & $0,481^{* *}$ & 0,058 & $-0,485^{* *}$ & $-0,033$ & $-0,236^{* *}$ & 1 \\
\hline
\end{tabular}

Nota. Fonte: Dados da pesquisa.

** A correlação é significativa no nível 0,01 (2 extremidades).

Verifica-se uma correlação negativa entre a participação orçamentária e a assimetria de informação, ambiguidade e conflito de papéis e o estresse no trabalho. Contudo, apenas as relações entre participação, ambiguidade e estresse são significativas. Estes resultados sugerem que maiores níveis de participação refletem em menores níveis de estresse no trabalho. A ambiguidade e conflito de papéis apresentaram relação positiva, mas não significativa. Apesar disto, quando combinadas, apresentam relação com o constructo de estresse no trabalho, que também está positivamente associado a maiores níveis de assimetria informacional.

A participação orçamentária está positivamente relacionada ao desempenho. Dentre as demais variáveis, apenas a ambiguidade de papéis e o estresse no trabalho apresentaram relação negativa com o desempenho. Estes resultados sugerem que maiores níveis de participação orçamentária reduzem os níveis de estresse ocupacional, impactando positivamente no desempenho.

Os resultados da análise de trajetórias são apresentados na Tabelas 3. 
Tabela 3

\section{Resultados da Análise de Trajetórias}

\begin{tabular}{|c|c|c|c|c|c|c|c|c|}
\hline $\begin{array}{c}\text { Variáveis } \\
\text { Dependentes }\end{array}$ & $\begin{array}{c}\text { Variáveis } \\
\text { Independentes }\end{array}$ & $\beta$ - standard & $t$-statistic & $P$-value & $\mathbf{R}^{2}$ & $\begin{array}{c}\text { Erro } \\
\text { Padrão }\end{array}$ & $\mathbf{F}$ & $\begin{array}{l}\text { Sig. } \\
\text { Anova }\end{array}$ \\
\hline AI & $\mathrm{PO}$ & $-0,046$ & $-0,498$ & 0,619 & 0,002 & 5,11368 & 0,248 & 0,619 \\
\hline $\mathrm{AP}$ & $\mathrm{PO}$ & $-0,640$ & $-9,082$ & 0,000 & 0,409 & 2,93043 & 82,487 & 0,000 \\
\hline $\mathrm{CP}$ & $\mathrm{PO}$ & $-0,101$ & $-1,113$ & 0,268 & 0,010 & 7,76720 & 1,238 & 0,268 \\
\hline ET & $\mathrm{PO}$ & $-0,362$ & $-4,234$ & 0,000 & 0,131 & 8,32843 & 17,923 & 0,000 \\
\hline DG & $\mathrm{PO}$ & 0,481 & 5,985 & 0,000 & 0,231 & 4,21556 & 35,818 & 0,000 \\
\hline DG & AI & 0,058 & 0,635 & 0,527 & 0,003 & 4,80019 & 0,403 & 0,527 \\
\hline DG & AP & $-0,485$ & $-6,048$ & 0,000 & 0,235 & 4,20531 & 36,574 & 0,000 \\
\hline DG & $\mathrm{CP}$ & $-0,101$ & $-0,033$ & $-0,363$ & 0,718 & 4,80566 & 0,131 & 0,718 \\
\hline DG & ET & $-0,236$ & $-2,649$ & 0,009 & 0,056 & 4,67251 & 7,018 & 0,009 \\
\hline \multirow{3}{*}{$\begin{array}{c}\text { DG } \\
\text { (Equação 01) }\end{array}$} & $\mathrm{PO}$ & 0,297 & 2,877 & 0,005 & \multirow{3}{*}{0,286} & \multirow{3}{*}{4,09855} & \multirow{3}{*}{15,595} & \multirow{3}{*}{0,000} \\
\hline & AI & 0,035 & 0,440 & 0,661 & & & & \\
\hline & $\mathrm{AP}$ & $-0,291$ & $-2,800$ & 0,006 & & & & \\
\hline \multirow{2}{*}{$\begin{array}{c}\text { DG } \\
\text { (Equação 01) }\end{array}$} & $\mathrm{PO}$ & 0,289 & 2,853 & 0,005 & \multirow{2}{*}{0,284} & \multirow{2}{*}{4,08452} & \multirow{2}{*}{23,455} & \multirow{2}{*}{0,000} \\
\hline & $\mathrm{AP}$ & $-0,300$ & $-2,959$ & 0,004 & & & & \\
\hline \multirow{3}{*}{$\begin{array}{c}\text { DG } \\
\text { (Equação 02) }\end{array}$} & $\mathrm{PO}$ & 0,483 & 5,959 & 0,000 & \multirow{3}{*}{0,238} & \multirow{3}{*}{4,23313} & \multirow{3}{*}{12,178} & \multirow{3}{*}{0,000} \\
\hline & $\mathrm{AI}$ & 0,085 & 0,988 & 0,325 & & & & \\
\hline & $\mathrm{CP}$ & $-0,015$ & $-0,168$ & 0,867 & & & & \\
\hline \multirow{3}{*}{$\begin{array}{c}\text { DG } \\
\text { (Equação 03) }\end{array}$} & $\mathrm{PO}$ & 0,449 & 5,212 & 0,000 & \multirow{3}{*}{0,246} & \multirow{3}{*}{4,21091} & \multirow{3}{*}{12,720} & \multirow{3}{*}{0,000} \\
\hline & $\mathrm{AI}$ & 0,105 & 1,256 & 0,212 & & & & \\
\hline & ET & $-0,100$ & $-1,125$ & 0,263 & & & & \\
\hline \multirow{4}{*}{$\begin{array}{c}\text { DG } \\
\text { (Equação 04) }\end{array}$} & $\mathrm{PO}$ & 0,297 & 2,866 & 0,005 & \multirow{4}{*}{0,286} & \multirow{4}{*}{4,11608} & \multirow{4}{*}{11,598} & \multirow{4}{*}{0,000} \\
\hline & AI & 0,033 & 0,381 & 0,704 & & & & \\
\hline & AP & $-0,294$ & $-2,540$ & 0,012 & & & & \\
\hline & ET & 0,007 & 0,074 & 0,941 & & & & \\
\hline \multirow{2}{*}{$\begin{array}{c}\text { DG } \\
\text { (Equação 05) }\end{array}$} & $\mathrm{PO}$ & 0,455 & 5,273 & 0,000 & \multirow{2}{*}{0,236} & \multirow{2}{*}{4,22120} & \multirow{2}{*}{18,202} & \multirow{2}{*}{0,000} \\
\hline & ET & $-0,071$ & $-0,826$ & 0,411 & & & & \\
\hline
\end{tabular}

Nota. Fonte: Dados da pesquisa. Descritivo: AI. Assimetria de Informação; AP. Ambiguidade de Papéis; CP. Conflito de Papéis; ET. Estresse Ocupacional; PO. Participação Orçamentária; DG. Desempenho Gerencial.

Os resultados das análises de trajetórias revelaram que a participação influencia direta e positivamente o desempenho gerencial em todos os caminhos avaliados. Estes achados convergem com os resultados encontrados por Dunk (1993), Nouri e Parker (1998), Chong e Chong (2002a), Chong et al. (2006), Parker e Kyj (2006), Chong e Johnson (2007) e Zonatto e Lavarda (2013). Todavia divergem das evidências encontradas por Chenhall e Brownell (1988), Chong e Chong (2002b), Cheng (2012) e Macinati, Bozzi e Rizzo (2016).

Deste modo, maiores níveis de participação orçamentária resultam em maior desempenho gerencial, o que sugere que a participação ativa dos gestores nos processos orçamentários e no 
compartilhamento de informações melhora o seu desempenho (Parker \& Kyj, 2006). Zonatto e Lavarda (2013) inferem que as características de ampla participação dos gestores nos processos orçamentários, o acesso a informação e a disseminação das práticas de gestão impactam positivamente o desempenho no trabalho.

Estudos voltados à área da contabilidade gerencial têm enfatizado amplamente os efeitos benéficos da participação orçamentária no desempenho dos gestores (Birnberg et al., 2006). Esta participação permite o envolvimento e a influência destes na determinação do orçamento de suas unidades (Chong \& Chong, 2002a; J. F. Shields \& Shields, 1998) e a socialização de informações. Esta relação positiva também pode ser explicada na visão de Derfuss (2009), pois este processo motiva os funcionários a atingir os objetivos organizacionais, alterando a percepção de trabalho, o que impacta positivamente no desempenho.

Estes resultados permitem aceitar a primeira hipótese de pesquisa:H1. Existe relação positiva entre a participação orçamentária e o desempenho gerencial. Ao sentir-se parte do processo orçamentário, gestores de unidades divisionais ficam mais propensos a compartilharem informações relevantes para as tarefas (Kren, 1992). De tal maneira, cria-se um ambiente favorável para a socialização de informações (Parker \& Kyj, 2006). Quando isto ocorre, há uma percepção de menores níveis de tensão relacionada ao trabalho, o que reduz a ambiguidade de papéis (Chenhall \& Brownell, 1988; M. D. Shields e al., 2000; Parker \& Kyj, 2006) e também os níveis de estresse ocupacional (M. D. Shields et al., 2000; Zonatto \& Lavarda, 2013).

Os achados encontrados nesta pesquisa corroboram com tais evidências, pois a participação orçamentária apresentou relação negativa e significativa com a ambiguidade de papéis e o estresse no trabalho. Assim, não se rejeitam as hipóteses H3a e H3c: H3. Existe relação negativa entre a participação orçamentária e a ambiguidade de papéis (H3a); e entre a participação orçamentária e o estresse ocupacional (H3c).

Estes resultados corroboram com os achados de Chenhall e Brownell (1988) e Jermias e Yigit (2013), para a ambiguidade de papéis, e de Zonatto e Lavarda (2013), para o estresse ocupacional. M. D. Shields et al. (2000) e Parker e Kyj (2006) sugerem que a participação orçamentária reduz a ambiguidade e o conflito de papéis e resulta em menores níveis de estresse ocupacional (Zonatto \& Lavarda, 2013), conforme constatado na presente pesquisa.

Chenhall e Brownell (1988) abordam que é por meio da participação orçamentária que os subordinados obtêm informações que os ajudam a esclarecer seus papéis organizacionais, o que minimiza a ambiguidade de papéis no ambiente de trabalho. Os resultados de Parker e Kyj (2006) indicam que a participação orçamentária direciona o indivíduo para o desenvolvimento de suas tarefas, fazendo com que este tenha certeza sobre suas expectativas organizacionais e os meios para atingir com êxito suas atividades. De acordo com Zonatto e Lavarda (2013), estes resultados revelam que fatores estressores do ambiente de trabalho podem ser resolvidos, bem como minimizados mediante a adoção de práticas orçamentárias nas organizações.

Hopwood (1976) aborda que, no processo orçamentário, os subordinados possuem a oportunidade de obter mais informações sobre suas tarefas, o que implica a diminuição do estresse ocupacional. Assim, por meio da participação orçamentária, torna-se possível minimizar a ambiguidade de papéis e o estresse no trabalho. Além disso, uma vez que os subordinados participam ativamente dos processos orçamentários, estes percebem que as condições de trabalho passam a ser mais adequadas para a realização de suas tarefas (Paschoal \& Tamayo, 2004), pois sentem-se mais próximos dos processos orçamentários. Os resultados sugerem ainda que a participação orçamentária proporciona a compreensão clara das atividades a serem desenvolvidas (Kahn et al., 1964) e uma estrutura de trabalho coerente com as demandas da organização (Rizzo et al., 1970).

Tais condições tendem a refletir positivamente no desempenho gerencial, o que resulta nos efeitos indiretos da participação sobre o desempenho (Derfuss, 2016; Dani et al., 2017). Estes achados foram constatados nesta pesquisa, sendo a relação entre a participação orçamentária e o desempenho 
gerencial mediada pela ambiguidade de papéis. Tais evidências corroboram com os de Chenhall e Brownell (1988), M. D. Shields et al. (2000), Parker e Kyj (2006), Chong et al. (2006), Jermias e Yigit (2013) e Zonatto e Lavarda (2013), o que permite aceitar a hipótese H5a: H5a. A ambiguidade de papéis medeia a relação entre a participação orçamentária e o desempenho gerencial.

Estes resultados sugerem que, ao participar dos processos orçamentários, os funcionários compartilham informações para a realização de suas tarefas (Kren, 1992; J. F. Shields \& Shields, 1998), o que contribui para obterem clareza de suas atividades (Chenhall \& Brownell, 1988; Kren, 1992) e da estrutura do trabalho (Burkert et al., 2011, Leach-López et al., 2008). Uma vez que a ambiguidade e o conflito de papéis são minimizados por meio da participação orçamentária, isso tende a apresentar reflexos positivos no desempenho.

As evidências encontradas revelam que as organizações devem apresentar explicações claras para os subordinados sobre o que deve ser feito, o tempo necessário para a realização da tarefa, juntamente com objetivos claros e planejados para o trabalho, a autoridade que os indivíduos possuem, o que se espera deles e quais são suas responsabilidades (Rizzo et al., 1970). Uma vez que os indivíduos estão cientes do seu trabalho participarão mais ativamente dos processos orçamentários (Milani, 1975) e, consequentemente, apresentarão melhores resultados gerenciais (Mahoney et al., 1963, 1965).

As análises sobre as hipóteses do grupo 5 inicialmente foram conduzidas para verificar os efeitos mediadores da ambiguidade de papéis na relação entre participação orçamentária e desempenho gerencial, conforme supracitado (H5a). Na sequência, são apresentados os resultados considerando-se os efeitos mediadores do estresse ocupacional nesta relação, de acordo com as informações apresentadas a seguir (H5c), e, por fim, as evidências encontradas para os efeitos mediadores do constructo de conflito de papéis (H5b) na relação entre participação orçamentária e desempenho gerencial.

Apesar de o estresse ocupacional apresentar relação negativa com a participação orçamentária e o desempenho gerencial (M. D. Shields et al., 2000; Zonatto \& Lavarda, 2013), nesta pesquisa, tais relacionamentos não foram confirmados. Considerando-se que os resultados desta relação contemplam a observância conjunta dos efeitos de ambiguidade e conflito de papéis (estresse ocupacional), como proposto por Paschoal e Tamayo (2004), estes achados podem estar relacionados à percepção dos gestores com as condições de trabalho.

Estes resultados sugerem que nem todos os fatores estressores no ambiente de trabalho puderam ser minimizados por meio da participação orçamentária. Mesmo assim, não apresentaram impactos significativos no desempenho gerencial, como constatado por M. D. Shields et al. (2000) e Zonatto e Lavarda (2013). Observa-se que apenas a consideração da participação orçamentária para a minimização do estresse ocupacional, talvez não seja o suficiente para melhorar a relação entre participação orçamentária e o desempenho gerencial. Estes achados reforçam a importância de se analisar os efeitos de estressores no trabalho sob uma perspectiva mais ampla, assim como proposto por Rizzo et al. (1970), levando em consideração tanto a ambiguidade de papéis e o conflito de papéis, de forma separada, como também estes elementos de análise de forma conjunta.

O constructo de conflito de papéis avalia se os gestores acreditam que determinadas atividades deveriam ser realizadas de maneira diferente, se recebem atribuições com pessoal considerado por eles insuficientes para desenvolverem suas tarefas e se as atribuições recebidas são compatíveis com os recursos e materiais destinados. Quando ocorre limitação de pessoal, materiais ou recursos, é normal que os níveis de estresse sejam elevados (Paschoal \& Tamayo, 2004; Leach-López et al., 2008; Burkert et al., 2011; Zonatto \& Lavarda, 2013). Nestes casos, a percepção de conflitos de papéis também emerge.

Contudo, não necessariamente os efeitos dos fatores estressores do ambiente impactarão de modo negativo no desempenho do indivíduo no trabalho (Cavanaugh et al., 2000; Mackie et al., 2001). Isto ocorre porque as reações individuais relacionadas aos estressores do ambiente variam de 
indivíduo para indivíduo (Selye, 1956). Há casos em que os gestores, mesmo a frente de tais condições, empenham-se ainda mais para assegurar que as metas e objetivos estabelecidos sejam alcançados. Nestas condições, mesmo aumentando os níveis de estresse ocupacional, é possível que os gerentes com alta participação orçamentária apresentem melhor desempenho. Assim, rejeitam-se as hipóteses $\mathrm{H} 3 \mathrm{~b}, \mathrm{H} 5 \mathrm{~b}$ e H5c: H3b. Existe relação negativa entre a participação orçamentária e o conflito de papéis; e H5. O conflito de papéis $(\mathrm{H5b})$ e o estresse ocupacional $(\mathrm{H5c})$ medeiam a relação entre a participação orçamentária e o desempenho gerencial.

Conforme Leach-López, Stammerjohan e McNair (2008), o conflito pode ser criado por qualquer atividade que resulte em diferenças entre os níveis experimentados e desejados de participar dos processos orçamentários. Nesse sentido, o fato dos participantes desta pesquisa se envolverem ativamente na definição dos orçamentos, não apresentou efeitos que minimizam o conflito de papéis, e este não apresentou efeitos mediadores na relação entre participação orçamentária e desempenho gerencial, o que implica que diminuir os conflitos não necessariamente melhora diretamente a participação orçamentária e o desempenho. Os resultados de Burkert, Fischer e Schäffer (2011) revelaram que o conflito e a ambiguidade de papéis são variáveis com potencial efeito mediador no contexto contábil alemão. Essa abordagem apenas foi observada nesta pesquisa para a ambiguidade de papéis.

Os resultados dos caminhos diretos entre as variáveis de ambiguidade, conflito de papéis e o estresse ocupacional apresentaram relação negativa com o desempenho. Contudo, foram significativos apenas os caminhos entre ambiguidade e desempenho e estresse e desempenho. Os resultados entre estas variáveis e a participação orçamentária também foram similares, indicando a mesma significância para estes caminhos e a participação. Estes achados revelam que quanto maior é a participação orçamentária, menores são os níveis de ambiguidade, conflito de papéis e estresse no trabalho e maiores são os níveis de desempenho gerencial.

Em relação à assimetria informacional, os achados da pesquisa não apresentaram relação significativa para os caminhos entre a assimetria e participação, e assimetria e o desempenho, o que permite rejeitar as hipóteses $\mathrm{H} 2$ e $\mathrm{H} 4$ : H2. Existe relação negativa entre a participação orçamentária e a assimetria de informação; e H4. Existe um efeito mediador da assimetria de informação na relação entre a participação orçamentária e o desempenho gerencial.

As evidências encontradas revelaram que alguns gestores percebem que seus superiores possuem melhores informações sobre as atividades de trabalho. Todavia, a assimetria não foi suficiente para impactar negativamente o desempenho. A assimetria apresentou relação negativa com o conflito de papéis, o que revela que mesmo em situações que os gestores percebem as condições de trabalho adequadas, os níveis de assimetria informacional são maiores, o que sugere que determinados gestores podem reter informações, de modo a obter um orçamento mais favorável ao alcance de seus objetivos orçamentários.

Estes resultados divergem dos estudos de Chow, Cooper e Waller (1988), M. D. Shields e Young (1993), J. F. Shields e Shields (1998), Fisher et al. (2002), Kyj e Parker (2008), Zonatto e Lavarda (2013) e Lavarda e Almeida (2013). Os argumentos de M. D. Shields e Young (1993) e J. F. Shields e Shields (1998), não puderam ser constatados, pois ressaltam que quanto maior o nível de participação, mais os superiores promovem a participação dos indivíduos nos processos orçamentários. Chong e Eggleton (2007) destacam que as diferenças nos resultados da assimetria de informação podem ser devido ao comportamento dos gestores. Lavarda e Almeida (2013) abordam que a participação orçamentária, por si só, pode não ser suficiente para minimizar a assimetria, havendo outros fatores que auxiliam nesta redução.

Diferenças entre os estudos que analisaram a assimetria informacional no contexto desta pesquisa, podem explicar os resultados divergentes. M. D. Shields e Young (1993) pesquisaram controladores de grandes organizações e a assimetria de informação foi medida no nível da empresa. A amostra atual são gestores com responsabilidades orçamentárias de organizações industriais brasileiras e a assimetria de informação é medida no nível do indivíduo. Fisher et al. (2002) pesquisaram alunos 
de graduação que estavam cursando a disciplina de contabilidade intermediária e, por meio de um experimento, os participantes foram induzidos a um cenário de assimetria de informação. Nesta pesquisa, utilizou-se de um questionário para a obtenção de respostas sobre a assimetria. Zonatto e Lavarda (2013), pesquisaram colaboradores de diferentes setores, em uma unidade regional de ensino profissional. A atual pesquisa analisou o contexto orçamentário de indústrias brasileiras de grande porte.

A Figura 1 apresenta a síntese dos resultados das relações encontradas para a confirmação dos efeitos direto e indireto da participação orçamentária sobre o desempenho gerencial.

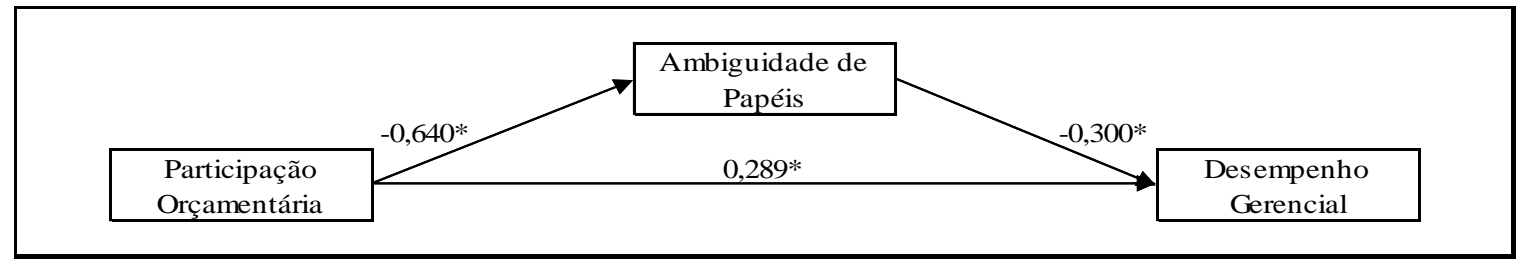

Figura 1. Análise de Caminhos das Relações Direta e Indireta Encontradas entre Participação e Desempenho $* p<0,01$.

$\mathrm{Na}$ amostra investigada, pode-se inferir que a participação orçamentária possui influência direta (Tabela 3) no desempenho gerencial (Efeito Direto PO $\rightarrow \mathrm{DG}=0,481$ ) e indireta (Figura 1), mediada pela ambiguidade de papéis (Efeito Direto PO $\rightarrow \mathrm{DG}=0,289+$ Efeito Indireto $\mathrm{PO} \rightarrow \mathrm{AP} \rightarrow \mathrm{DG}=-$ $0,640 \times-0,300=0,192=$ Efeito Total $=0,289+0,192=0,481)$.

Em relação aos efeitos diretos, pode-se inferir que as percepções dos gestores sobre a parcela do orçamento que está envolvido, o tipo de raciocínio que este forneceu para um superior quando o orçamento é revisado, as discussões realizadas sobre o orçamento, a influência que os gestores possuem sobre o orçamento e a importância da sua contribuição para a definição do orçamento de sua unidade (Milani, 1975) são questões fundamentais que passam a afetar positivamente o desempenho dos gestores no desenvolvimento de suas funções orçamentárias, relacionadas ao planejamento, investigação, coordenação, avaliação, supervisão, seleção, negociação, representação, que também influenciam o desempenho global do gestor (Mahoney et al., 1963, 1965).

No que tange aos efeitos indiretos, estes resultados reforçam as evidências relacionadas aos efeitos intervenientes na relação entre participação e desempenho (Dani et al., 2017; Derfuss, 2016). Os resultados dos efeitos indiretos da ambiguidade de papéis na relação entre participação e desempenho também foram constatados pelos estudos de Chenhall e Brownell (1988), Chong et al. (2006) e Jermias e Yigit (2013).

Diante deste resultado, percebe-se que a participação orçamentária possui o potencial de esclarecer informações sobre as expectativas das tarefas, métodos para cumpri-las e as consequências do desempenho das tarefas, o que impacta positivamente o desempenho gerencial (Chenhall \& Brownell, 1988; Jermias \& Yigit, 2013). Estes resultados contradizem a previsão da teoria da agência (assimetria de informação). Contudo, destacam por meio da variável ambiguidade de papéis que os superiores sentem-se responsáveis pelas atividades dos subordinados, e estes exibem lealdade diante dos superiores (Jermias \& Yigit, 2013).

A análise sobre os efeitos intervenientes do estresse ocupacional, oportunizou compreender que os gestores pesquisados percebem o conflito de papéis e a ambiguidade como elementos presentes em seu ambiente de trabalho. Do mesmo modo, revela a existência de assimetria de informação neste ambiente, o que sugere que esta se constitui um elemento natural presente nos processos orçamentários das empresas, que poderá ou não ser mitigada pela participação dos indivíduos nestes processos. 
A participação orçamentária atuou como um instrumento de gestão capaz de reduzir apenas a ambiguidade presente no contexto orçamentário, visto que o mesmo não se observou em relação ao conflito de papéis. Uma alternativa para que os gestores possam superar as restrições presentes no ambiente está relacionada à necessidade de maior envolvimento e esforço para o desenvolvimento de suas atividades, de modo que o desempenho seja alcançado, mesmo em situações em que as condições de trabalho possam não ser as mais adequadas.

Estes achados reforçam a relevância de se investigar o estresse ocupacional não apenas como um índice global, mas sim como elementos específicos de análise presentes no contexto de trabalho, que podem afetar a ação e o comportamento dos indivíduos no desenvolvimento de suas atividades, refletindo positiva ou negativamente, no desempenho.

Considerando-se tais evidências, procurou-se avaliar em um novo modelo de regressão se as variáveis utilizadas para o estabelecimento do perfil dos gestores são capazes de influenciar tais relacionamentos, fornecendo explicações para eventuais diferenças na amostra analisada. Na Tabela 4 são apresentados os resultados da análise adicional realizada.

Tabela 4

\section{Resultados da Análise Adicional}

\begin{tabular}{|c|c|c|c|c|c|c|c|c|}
\hline $\mathbf{x}$ & Variáveis Dependentes $\rightarrow$ & & PO & AI & $\mathbf{A P}$ & $\mathbf{C P}$ & ET & DG \\
\hline \multirow{6}{*}{ 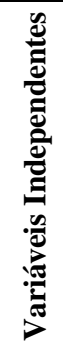 } & Tempo de Trabalho na Empresa & \multirow{6}{*}{ ن } & $-0,167$ & 0,091 & $-0,082$ & 0,004 & 0,086 & 0,006 \\
\hline & Tempo de Trabalho na Função & & 0,082 & $-0,074$ & 0,033 & 0,175 & 0,142 & $-0,106$ \\
\hline & Nível Hierárquico & & 0,314 & $-0,649$ & 0,506 & $-1,267$ & $-1,773^{*}$ & 0,712 \\
\hline & Uso Orçamento para Avaliação de Desempenho & & 0,400 & 0,732 & $0,565^{*}$ & 0,661 & 0,096 & $0,642 *$ \\
\hline & Nível de Conhecimentos em Gestão de Custos & & 0,189 & $-0,224$ & 0,663 & $2,197 *$ & 1,534 & 0,063 \\
\hline & Nível de Conhecimentos em Rotinas e Processos Orçamentários & & $1,629 *$ & 0,073 & 0,332 & $-0,966$ & $-1,299$ & 1,108 \\
\hline $\mathbf{R}^{2}$ & & & 0,231 & 0,050 & 0,276 & 0,070 & 0,078 & 0,252 \\
\hline Sig. & Anova & & 0,000 & 0,427 & 0,000 & 0,210 & 0,149 & 0,000 \\
\hline
\end{tabular}

Nota. Descritivo: PO. Participação Orçamentária; AI. Assimetria de Informação; AP. Ambiguidade de Papéis; CP. Conflito de Papéis; ET. Estresse Ocupacional; DG. Desempenho Gerencial. Fonte: Dados da pesquisa.

* Significância ao nível de 5\%.

Com base nos resultados evidenciados na Tabela 4, pode-se observar que o nível de conhecimentos em rotinas e processos orçamentários relaciona-se com a participação orçamentária, o que revela que quanto mais conhecimento os gestores possuírem do contexto orçamentário, melhor será sua participação nos processos orçamentários. No que diz respeito à ambiguidade de papéis e o desempenho gerencial, a utilização do orçamento para avaliação de desempenho se relaciona positivamente com estas variáveis. Este resultado assemelha-se aos achados de Hopwood (1972), visto que os autores encontraram evidências de que a utilização do orçamento para a avaliação do desempenho dos subordinados resultou em alta tensão relacionada ao trabalho, o que, consequentemente, diminui o desempenho do indivíduo.

A partir deste resultado, Brownell (1982b) argumenta que o efeito da utilização do orçamento para avaliação dos subordinados é moderado pela participação orçamentária. Assim, ressalta-se os efeitos potenciais da participação orçamentária no ambiente de trabalho. Lau e Buckland (2001) abordam que a partir do momento em que os objetivos orçamentários são utilizados para avaliar os subordinados, estes procuram participar do processo de definição do orçamento. Deste modo, a participação orçamentária possui o potencial de minimizar a ambiguidade de papéis e melhorar o desempenho dos indivíduos no trabalho (Chenhall \& Brownell, 1988; Chong et al., 2006; Jermias \& Yigit, 2013). 
O conhecimento em gestão de custos relaciona-se com o conflito de papéis, o que sugere que os gestores com um nível de conhecimento inferior sobre gestão de custos, apresentarão maior conflito de papéis (Rizzo et al., 1970). Agbejule e Saarikoski (2006) abordam que as organizações devem melhorar o conhecimento de gestão de custos dos gestores que participam do processo orçamentário, o que minimizará o conflito de papéis.

O estresse ocupacional se apresentou relacionado negativamente com o nível hierárquico, o que sugere que o nível hierárquico minimiza o estresse no ambiente de trabalho. De acordo com Katz e Kahn (1966), o nível hierárquico dos gestores pode ser considerado um fator de contexto central. Este resultado é convergente com estudos realizados na área contábil (Davis \& Kohlmeyer, 2005; Dunk, 1992). Burkert et al. (2011) abordam que os gestores em níveis mais altos tendem a ser mais propensos a aceitar uma falta de controle orçamentário quando comparados aos gestores que ocupam níveis hierárquicos mais baixos e podem sofrer menos estresse no trabalho quando confrontados com fatores incontroláveis.

A assimetria de informação não se relacionou com o perfil dos gestores, o que indica que a ocorrência de assimetria no ambiente de trabalho independe do tempo de trabalho na empresa e na função, nível hierárquico, utilização do orçamento para fins de avaliação do desempenho dos gestores, nível de conhecimentos em gestão de custos e em rotinas e processos orçamentários, o que também pode ser confirmado com a análise de trajetórias. Os estudos desenvolvidos por Fisher et al. (2002), Lavarda e Almeida (2013) e Jermias e Yigit (2013) também não encontraram evidências que a participação orçamentária minimiza os níveis de assimetria de informação, culminando em melhor desempenho no trabalho.

De modo geral, os resultados encontrados a partir desta análise revelaram que tais variáveis discriminam os efeitos encontrados nos relacionamentos analisados no estudo. Além disso, denota-se que o perfil da amostra pode ter refletido nos resultados da pesquisa, principalmente diante dos resultados obtidos da assimetria de informação.

\section{Conclusões}

Este artigo contribui para a literatura ao examinar os efeitos da participação orçamentária na assimetria de informação, no estresse ocupacional e no desempenho gerencial e por investigar um conjunto de variáveis intervenientes na relação entre participação e desempenho. Do ponto de vista teórico, complementa o estudo desenvolvido por Zonatto e Lavarda (2013), pois se analisaram variáveis de controle (perfil dos respondentes), com vistas a avaliar em que medida o perfil da amostra reflete nos resultados da pesquisa e relaciona-se com as variáveis analisadas, diferente do proposto por esses autores, e promove a análise do estresse e do desempenho gerencial sob uma perspectiva distinta e mais ampla.

Uma implicação importante deste estudo é que a ambiguidade de papéis mostrou-se um elo importante entre participação orçamentária e desempenho. Estes resultados são consistentes com a visão de que a participação orçamentária minimiza a ambiguidade de papéis dos gerentes e melhora o desempenho do indivíduo nas atividades orçamentárias (Chenhall \& Brownell, 1988; Chong et al., 2006; Jermias \& Yigit, 2013).

Nesse sentido, embora estudos anteriores tenham analisado a relação entre algumas das variáveis incluídas no atual modelo de pesquisa (Zonatto \& Lavarda, 2013), os resultados contribuem para a abordagem comportamental das práticas contábeis gerenciais (Covaleski, Evans, Luft, \& Shields, 2003) ao lançar luz sobre efeitos diretos e relações indiretas distintas entre as variáveis consideradas, anteriormente pouco exploradas na literatura.

As evidências encontradas na pesquisa reforçam os achados sobre os efeitos dos papéis informativos da participação dos gestores nos processos orçamentários como um meio eficiente para 
se reduzir os níveis de ambiguidade de papéis e melhorar o desempenho de gerentes subordinados. Maiores níveis de participação orçamentária refletem em maior confiança entre os gestores, o que favorece a partilha de informações relevantes para as tarefas, melhora a comunicação entre os gestores, de modo que se possa facilitar a definição de metas e objetivos orçamentários, bem como alocar melhor os recursos necessários a cada unidade, com vistas a viabilizar o desenvolvimento de suas atividades e o alcance de tais objetivos.

Os achados revelam ainda que, mesmo não sendo significativos, ambos os caminhos entre participação orçamentária e assimetria informacional, e participação orçamentária e conflito de papéis foram negativos. Estes resultados fornecem indícios de que gestores que percebem maior influência nos processos orçamentários são aqueles mais propensos a apresentar menores níveis de assimetria informacional e conflito de papéis. Resultados contrários foram os encontrados por Zonatto e Lavarda (2013), pois as evidências daquele estudo indicaram uma correlação negativa entre a participação orçamentária e o estresse ocupacional e a assimetria de informação, o que revela que fatores estressores do ambiente de trabalho e problemas de assimetria podem ser resolvidos com a participação orçamentária (Zonatto \& Lavarda, 2013).

Estes achados fornecem indícios da importância de se investigar os estressores de maneira distinta a análise realizada por Zonatto e Lavarda (2013), de modo que se possa melhor compreender seus efeitos em diferentes amostras. Revelam também que variáveis contextuais e de perfil podem afetar tais relacionamentos, o que se constitui outra contribuição teórica desta pesquisa. Adicionalmente, estes resultados corroboram com os de Lavarda e Almeira (2013), indicando que, em determinados contextos, talvez a participação orçamentária não seja suficiente para reduzir os níveis de assimetria informacional.

A associação negativa e significativa entre um melhor desempenho gerencial e menores níveis de ambiguidade de papéis e estresse no trabalho revelam efeitos indiretos da participação orçamentária sobre o desempenho. Isto ocorre porque os gestores tendem a se sentir mais seguros em relação a sua autoridade, responsabilidade no trabalho e suas tarefas, e ao conhecimento das metas e objetivos pelas quais serão avaliados. A clareza na comunicação entre a gerência superior e a média gerência contribui para a otimização dos recursos organizacionais e o alcance de melhor desempenho.

Os resultados obtidos a partir da variável estresse ocupacional constituem-se importante contribuição teórica deste estudo, uma vez que apresentam indícios de efeitos distintos de alguns estressores, quando analisados de maneira global ou individual, mediante a observância de determinados estressores do ambiente, como nesta pesquisa, a ambiguidade e o conflito de papéis. Em relação à assimetria de informação, os resultados também revelam contribuições teóricas, uma vez que indicam em que condições a configuração orçamentária pode afetar negativamente o desempenho do gerente no trabalho, alimentando a assimetria informacional existente no contexto orçamentário e os níveis de estresse ocupacional. Contudo, mesmo observando-se que tais evidências elevam os níveis de estresse ocupacional, os gestores conseguem alcançar melhor desempenho gerencial. Tais achados reforçam as evidências de que gerentes de nível médio, com responsabilidade orçamentária, podem reagir de maneira diferente frente aos estressores ambientais, positiva ou negativamente.

Os resultados da pesquisa também apresentam implicações para a prática das organizações. Do ponto de vista gerencial, esta pesquisa direciona para o entendimento de como os gestores assumem responsabilidades no processo orçamentário e aumentam o conhecimento de como as práticas organizacionais e os papéis estão ligados uns com os outros, ou seja, como a participação possibilita minimizar a ambiguidade de papéis e, consequentemente, melhorar o desempenho gerencial. De tal maneira, o estudo apresenta evidências de que a ambiguidade de papéis influencia na relação entre participação orçamentária e desempenho gerencial. Assim, as empresas devem projetar a participação orçamentária de modo que permita que os funcionários tenham conhecimento para o desenvolvimento de suas tarefas e deve ser capaz de reduzir a assimetria de informação e o estresse ocupacional, visto que estas questões são importantes para os gestores desenvolverem suas tarefas e funções. 
Os resultados sugerem ainda que as organizações devem estimular os gestores a obterem um nível de conhecimento em gestão de custos e rotinas e processos orçamentários, pois o conhecimento aprimorado destas questões pode auxiliar na diminuição da ambiguidade e conflito de papéis, estresse ocupacional, além de melhorar o desempenho dos gestores nas atividades. A utilização do orçamento para fins de avaliação do desempenho dos gestores também é algo que é indicado para as organizações a partir dos resultados constatados nesta pesquisa, visto que auxilia na redução da ambiguidade de papéis presente no contexto orçamentário.

Tais evidências, mesmo que apresentem limitações, estimulam a realização de novos estudos. A este respeito, há que se considerar, ainda, que elementos fora do contexto de trabalho também podem resultar em estresse ocupacional, influenciando o desempenho gerencial. Relacionar aspectos organizacionais com psicológicos requer cuidados especiais já que o indivíduo pode ter outros elementos causadores de estresse que venham a se manifestar no trabalho, sem necessariamente terem o trabalho como causador do estresse. Os resultados encontrados nesta pesquisa apresentam, de certo modo, indícios relacionados a esse problema, já que na análise das hipóteses não se confirmam todas as relações investigadas.

Nesta pesquisa, optou-se por um conjunto de variáveis. Deste modo, outras variáveis que podem capturar tais elementos de análise constituem-se em novas oportunidades de pesquisa. Observar os efeitos das capacidades psicológicas dos indivíduos pode fornecer um referencial explicativo para as condições em que os estressores tendem a afetar negativa ou positivamente as ações, comportamentos e o desempenho dos indivíduos no trabalho. Além disso, observar os efeitos do envolvimento e motivação dos gestores e suas condições de suporte de trabalho também se constitui oportunidades para a realização de novos estudos. Adicionalmente, é oportuno investigar outros efeitos cognitivos, motivacionais e do valor de realização da participação orçamentária no desempenho gerencial, bem como os efeitos de antecedentes à participação e variáveis intervenientes do desempenho.

\section{Material Suplementar}

Como procedimentos éticos adotados quando da realização da coleta dos dados necessários a realização desta pesquisa, declarou-se aos participantes que os dados coletados não seriam divulgados, sendo tratados estatisticamente e de maneira consolidada. Nesta ocasião, também foi assegurado aos participantes que apenas os resultados estatísticos consolidados da pesquisa seriam divulgados para fins acadêmicos, sendo essas informações apresentadas por meio de quadros, figuras e/ou tabelas. Por esta razão os autores não disponibilizaram sua base de dados.

\section{Agradecimentos}

À Coordenação de Aperfeiçoamento de Pessoal de Nível Superior (CAPES), ao Conselho Nacional de Desenvolvimento Científico e Tecnológico (CNPq) e a Universidade Regional de Blumenau (FURB). Artigo relacionado ao Projeto "Pesquisas em desempenho gerencial de gestores com responsabilidade orçamentária” (Processo: 472195/2014-0).

\section{Contribuições}

$1^{\circ}$ autor: Definição do problema de pesquisa, desenvolvimento das hipóteses (trabalhos empíricos), fundamentação teórica/revisão da literatura, definição dos procedimentos metodológicos, análise estatística, análise e interpretação dos dados, revisão crítica do manuscrito, redação final do manuscrito

$2^{\circ}$ autor: Coleta dos dados, tabulação e análise inicial.

$3^{\circ}$ autor: Fundamentação teórica/revisão da literatura, coleta dos dados. 


\section{Referências}

Agbejule, A., \& Saarikoski, L. (2006). The effect of cost management knowledge on the relationship between budgetary participation and managerial performance. The British Accounting Review, 38(4), 427-440. https://doi.org/10.1016/j.bar.2006.06.003

Baiman, S. (1990). Agency research in managerial accounting: A second look. Accounting, Organizations and Society, 15(4), 341-371. https://doi.org/10.1016/0361-3682(90)90023-N

Birnberg, J. G., Luft, J., \& Shields, M. D. (2006). Psychology theory in management accounting research. Handbooks of Management Accounting Research, 1, 113-135. https://doi.org/10.1016/S1751-3243(06)01004-2

Brownell, P. (1982a). Participation in the budgeting process: When it works and when it doesn't. Journal of Accounting Literature, 1, 124-153. https://doi.org/10.2307/2490760

Brownell, P. (1982b). The role of accounting data in performance evaluation, budgetary participation, and organizational effectiveness. Journal of Accounting Research, 20(1), 12-27. https://doi.org/10.2307/2490760

Burkert, M., Fischer, F. M., \& Schäffer, U. (2011). Application of the controllability principle and managerial performance: The role of role perceptions. Management Accounting Research, 22(3), 143-159. https://doi.org/10.1016/j.mar.2011.03.002

Cavanaugh, M. A., Boswell, W. R., Roehling, M. V., \& Boudreau, J. W. (2000). An empirical examination of self-reported work stress among US managers. Journal of Applied Psychology, 85(1), 65-74. https://doi.org/10.1037//0021-9010.85.1.65

Cheng, M.-T. (2012). The Joint effect of Budgetary Participation and Broad Scope Management Accounting Systems on Management Performanc. Asian Review of Accounting, 20(3), 184-197. https://doi.org/10.1108/13217341211263256

Chenhall, R. H., \& Brownell, P. (1988). The effect of participative budgeting on job satisfaction and performance: Role ambiguity as an intervening variable. Accounting, Organizations and Society, 13(3), 225-233. https://doi.org/10.1016/0361-3682(88)90001-3

Chong, V. K., \& Chong, K. M. (2002a). Budget goal commitment and informational effects of budget participation on performance: A structural equation modeling approach. Behavioral Research in Accounting, 14(1), 65-86. https://doi.org/10.2308/bria.2002.14.1.65

Chong, V. K., \& Chong, K. M. (2002b). The role of feedback on the relationship between budgetary participation and performance. Pacific Accounting Review, 14(2), 33-55. https://doi.org/10.1108/eb037966

Chong, V. K., \& Eggleton, I. R. (2007). The impact of reliance on incentive-based compensation schemes, information asymmetry and organisational commitment on managerial $\begin{array}{llll}\text { performance. Management } \quad \text { Accounting } & \text { Research, 18(3), }\end{array}$ https://doi.org/10.1016/j.mar.2007.04.002

Chong, V. K., Eggleton, I. R., \& Leong, M. K. (2006). The multiple roles of participative budgeting on job performance. Advances in Accounting, 22, 67-95. https://doi.org/10.1016/S08826110(06)22004-2

Chong, V. K., \& Johnson, D. M. (2007). Testing a model of the antecedents and consequences of budgetary participation on job performance. Accounting and Business Research, 37(1), 3-19. https://doi.org/10.1080/00014788.2007.9730055 
Chow, C. W., Cooper, J. C., \& Waller, W. S. (1988). Participative budgeting: Effects of a truthinducing pay scheme and information asymmetry on slack and performance. Accounting Review, 63(1), 111-122.

Covaleski M. A., Evans J. H., Luft J. L., \& Shields M. D. (2003). Budgeting research: Three theoretical perspectives and criteria for selective integration. Journal of Management Accounting Research, 15(1), 3-49. https://doi.org/10.2308/jmar.2003.15.1.3

Covaleski, M., Evans, J. H., Luft, J., \& Shields, M. D. (2006). Budgeting research: Three theoretical perspectives and criteria for selective integration. Handbooks of Management Accounting Research, 2, 587-624. https://doi.org/10.1016/S1751-3243(06)02006-2

Dani, A. C., Zonatto, V. C. S., \& Diehl, C. A. (2017). Participação orçamentária e desempenho gerencial: Uma meta-análise das relações encontradas em pesquisas desenvolvidas na área comportamental da contabilidade. Advances in Scientific and Applied Accounting, 10(1), 54-72. http://doi.org/10.14392/asaa.2017100104

Davila, T., \& Wouters, M. (2005). Managing budget emphasis through the explicit design of conditional budgetary slack. Accounting, Organizations and Society, 30(7/8), 587-608. https://doi.org/10.1016/j.aos.2004.07.002

Davis, S., \& Kohlmeyer, J. M. (2005). The impact of employee rank on the relationship betweenattitudes, motivation and performance. In M. J. Epstein \& J. Y. Lee (Eds.), Advances in management accounting (pp. 233-252). Amsterdam: JAI Press Inc.

Derfuss K. (2009). The relationship of budget participation and reliance on accounting performance measures with individual-level consequent variables: A meta-analysis. European Accounting Review, 18(2), 203-240. https://doi.org/10.1080/09638180802652371

Derfuss, K. (2016). Reconsidering the participative budgeting-performance relation: A meta-analysis regarding the impact of level of analysis, sample selection, measurement, and industry $\begin{array}{llll}\text { influences. } \quad \text { The } & \text { British Accounting }\end{array}$ https://doi.org/10.1016/j.bar.2015.07.001

Dunk, A. S. (1992). The effects of managerial level on the relationship between budgetary participation and job satisfaction. The British Accounting Review, 24(3), 207-218. https://doi.org/10.1016/S0890-8389(05)80020-4

Dunk, A. S. (1993). The effect of budget emphasis and information asymmetry on the relation between budgetary participation and slack. Accounting Review, 68(2), 400-410.

Fisher, J., Frederickson, J. R., \& Peffer, S. A. (2002). The effect of information asymmetry on negotiated budgets: An empirical investigation. Accounting, Organizations and Society, 27(1/2), 27-43. https://doi.org/10.1016/S0361-3682(01)00046-0

Hansen, S. C., \& Van der Stede, W. A. (2004). Multiple facets of budgeting: an exploratory analysis. Management Accounting Research, 15(4), 415-439. https://doi.org/10.1016/j.mar.2004.08.001

Hopwood, A. G. (1972). An empirical study of the role of accounting data in performance evaluation. Journal of Accounting Research, 10 (Suppl.), 156-182. https://doi.org/10.2307/2489870

Hopwood, A. (1976). Accounting and human behavior. Englewood Cliffs, NJ: Prentice Hall.

Jermias, J., \& Yigit, F. (2013). Budgetary participation in Turkey: The effects of information asymmetry, goal commitment, and role ambiguity on job satisfaction and performance. Journal of International Accounting Research, 12(1), 29-54. https://doi.org/10.2308/jiar-50385 
Jensen, M. C., \& Meckling, W. H. (1976). Theory of the firm: Managerial behavior, agency costs and ownership structure. Journal of Financial Economics, 3(4), 305-360. https://doi.org/10.1016/0304-405X(76)90026-X

Hair, J. F., Black, W. C., Babin, B. J., Anderson, R. E., \& Tatham, R. L. (2009). Análise multivariada de dados. Porto Alegre: Bookman Editora.

Kahn, R. L., Wolfe, M., Quinn, R. P., Snoek, J. D., Rosenthal, R. A. (1964). Organizational stress. New York, NY: John Wiley \& Sons.

Katz, D., \& Kahn, R. L. (1966). The social psychology of organizations. New York: John Wiley \& Sons, Inc.

Kren, L. (1992). Budgetary participation and managerial performance: The impact of information and environmental volatility. The Accounting Review, 67(3), 511-526.

Kyj, L., \& Parker, R. J. (2008). Antecedents of budget participation: Leadership style, information

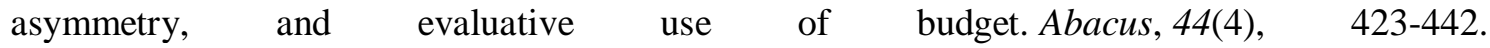
https://doi.org/10.1111/j.1467-6281.2008.00270.x

Lau, C., \& Buckland, C. (2001). Budgeting - the role of trust and participation: A research note. Abacus, 37(3), 369-388. https://doi.org/10.1111/1467-6281.00092

Lau, C. M., \& Eggleton, I. R. (2004). Cultural differences in managers' propensity to create slack. Advances in International Accounting, 17, 137-174. https://doi.org/10.1016/S08973660(04)17008-6

Lavarda, C. E. F., \& Almeida, D. M. (2013). Participação orçamentária e assimetria informacional: Um estudo em uma empresa multinacional. Brazilian Business Review, 10(2), 74-96.

Leach-López, M. A., Stammerjohan, W. W., \& McNair, F. M. (2008). Effects of budgetary participation conflict on job performance of Mexican and US managers. Advances in Accounting, 24(1), 49-64. https://doi.org/10.1016/j.adiac.2008.05.008

Macinati, M. S., Bozzi, S., \& Rizzo, M. G. (2016). Budgetary participation and performance: The mediating effects of medical managers' job engagement and self-efficacy. Health Policy, 120(9), 1017-1028. https://doi.org/10.1016/j.healthpol.2016.08.005

Mackie, K. S., Holahan, C. K., \& Gottlieb, N. H. (2001). Employee involvement management practices, work stress, and depression in employees of a human services residential care facility. Human Relations, 54(8), 1065-1092. https://doi.org/10.1177/0018726701548004

Mahoney, T. A., Jerdee, T. H., \& Carroll, S. J. (1963). Development of managerial performance: A research approach. Cincinnati: South Western Publ.

Mahoney, T. A., Jerdee, T. H., \& Carroll, S. J. (1965). The job (s) of management. Industrial Relations: A Journal of Economy and Society, 4(2), 97-110. https://doi.org/10.1111/j.1468232X.1965.tb00922.x

Milani, K. (1975). The relationship of participation in budget-setting to industrial supervisor performance and attitudes: a field study. The Accounting Review, 50(2), 274-284.

Nouri, H., \& Parker, R. J. (1998). The relationship between budget participation and job performance: the roles of budget adequacy and organizational commitment. Accounting, Organizations and Society, 23(5/6), 467-483. https://doi.org/10.1016/S0361-3682(97)00036-6 
Palomino, M. N., \& Frezatti, F. (2016). Conflito de papel, ambigüidade de função e satisfação no trabalho: Percepções dos controladores brasileiros. Revista de Administração, 51(2), 165-181. http://doi.org/10.5700/rausp1232

Penno, M. (1984). Asymmetry of pre-decision information and managerial accounting. Journal of Accounting Research, 22(1), 177-191. https://doi.org/10.2307/2490707

Parker, R. J., \& Kyj, L. (2006). Vertical information sharing in the budgeting process. Accounting, Organizations and Society, 31(1), 27-45. https://doi.org/10.1016/j.aos.2004.07.005

Paschoal, T., \& Tamayo, Á. (2004). Validação da escala de estresse no trabalho. Estudos de Psicologia, 9(1), 45-52. http://doi.org/10.1590/S1413-294X2004000100006

Pereira, A., Medeiros, A., Lopes, P., Ataíde, R., Pinto, C., Motta, E., \& Bernardino, O. (2003, julho). University student stress inventory: An exploratory study. Proceedings of the International Conference of the Stress and Anxiety, Book of Abstracts, Lisboa, Portugal, 24.

Rizzo, J. R., House, R. J., \& Lirtzman, S. I. (1970). Role conflict and ambiguity in complex organizations. Administrative Science

Quarterly, $15(2)$ 150-163. http://doi.org/10.2307/2391486

Selye, H. (1956). The stress of life. New York: McGraw-Hill Book Co.

Shields, J. F., \& Shields, M. D. (1998). Antecedents of budgetary participation. Accounting Organizations and Society, 23(1), 49-76. https://doi.org/10.1016/S0361-3682(97)00014-7

Shields, M. D., Deng, F. J., \& Kato, Y. (2000). The design and effects of control systems: tests of direct-and indirect-effects models. Accounting, Organizations and Society, 25(2), 185-202. https://doi.org/10.1016/S0361-3682(99)00041-0

Shields, M. D., \& Young, S. M. (1993). Antecedents and consequences of participative budgeting: evidence on the effects of asymmetrical information. Journal of Management Accounting Research, 5(1), 265-280.

Ursin, H., \& Eriksen, H. R. (2004). The cognitive activation theory of stress. Psychoneuroendocrinology, 29(5), 567-592. https://doi.org/10.1016/S0306-4530(03)00091-X

Zonatto, V. C. da S. (2014). Influência de fatores sociais cognitivos de capacidade, vontade e oportunidade sobre o desempenho gerencial nas atividades orçamentárias das maiores empresas exportadoras do Brasil (Tese de doutorado). Universidade Regional de Blumenau, Blumenau, SC, Brasil.

Zonatto, V. C. da S., \& Lavarda, C E. F. (2013). Evidências dos efeitos da participação orçamentária na assimetria de informação, estresse ocupacional e desempenho no trabalho. Advances in Scientific and Applied Accounting, 6(1), 92-111. https://doi.org/10.14392/ASAA/2013060105 


\section{Autores}

Vinicius Costa da Silva Zonatto

Rua Antônio da Veiga, 140, Itoupava Seca, 89030-903, Blumenau, SC, Brasil.

E-mail: viniciuszonatto@gmail.com

Aline Weber

Rua Antônio da Veiga, 140, Itoupava Seca, 89030-903, Blumenau, SC, Brasil.

E-mail: aline_weber@hotmail.com

Juliana Constâncio Nascimento

Rua Antônio da Veiga, 140, Itoupava Seca, 89030-903, Blumenau, SC, Brasil.

E-mail: jcbrida@hotmail.com, prof.juconstancio@gmail.com 